\title{
No encalço das mulheres de Chicago: conexões orgânicas e radicais do pragmatismo clássico americano'
}

\section{On the trail of Chicago women: organic and radical connections of classic american pragmatism}

Maria João Silveirinha

Professora Associada da Faculdade de Letras da Universidade de Coimbra, FLUC, Portugal $<$ mjsilveirinha@sapo.pt $>$

\section{RESUMO}

No nosso texto procuramos reencontrar as ligações pragmáticas desenvolvidas em Chicago na viragem para o século XX a uma visão feminista da sociedade como um todo orgânico. Para o efeito, revisitamos o contributo de Jane Addams, uma das pioneiras teóricas sociais americanas. Embora não diretamente associada com a Escola de Chicago, o seu trabalho seria muito influente para diversos autores da Escola que também a influenciaram. Destes, destacamos particularmente John Dewey e tentamos estabelecer as ligações entre o seu pensamento sobre a comunidade, o centramento do pragmatismo americano clássico na comunicação e as transformações feministas da ética. Concluímos com uma referência à urgência de reler Addams e Dewey nos seus entendimentos de comunidade, em tempos neoliberais que levaram ao recente fecho do que restava, em termos práticos, do importante trabalho de Jane Addams nas comunidades que ela procurou desenvolver e fortificar.

Palavras-chave: Jane Addams. Pragmatismo clássico. Feminismo.

\begin{abstract}
In our text we seek to find the programmatic links developed in Chicago at the turn of the twentieth century to a feminist vision of society as an organic whole. To this end, we revisit the contribution of Jane Addams, of the pioneers of American social theory. Although not directly associated with the Chicago School, her work was very influential to several authors of the School who also influenced her. Of these, we particularly highlight John Dewey as we establish the links between his thoughts on community, the focus of classic American pragmatism on communication and a feminist transformation of ethics. We conclude with a reference to urgency of rereading Addams and Dewey in their understandings of the community in the current neoliberal times that led to the recent closing of what was left, in practical terms, of Janes Addams' important work on the communities she sought to develop and strengthen.
\end{abstract}

Keywords: Jane Addams. Classical pragmatism. Feminism.

\section{Introdução: do pragmatismo ao feminismo}

Num estimulante trabalho sobre os cruzamentos e ligações entre 0 pragmatismo e o feminismo Charlene Haddock Seigfried apela à "redescoberta

1 Investigação produzida no contexto do projeto "Género e produção noticiosa: uma análise da produção e das organizações noticiosas em termos de género", financiado pela Fundação para a Ciência e Tecnologia (PTDC/IVC-COM/4881/2012). 
das mulheres pragmáticas", defendendo que o "panteão branco e masculino do pragmatismo precisa de ser alargado de modo a incluir as contribuições das mulheres" (Seigfried, 1991, p. 8). O trabalho de Seigfried (1991, 1996, 1999) constitui um relato histórico sobre a marginalização do trabalho das primeiras mulheresacadêmicas e sobreas razões que contribuíram para queo pragmatismo clássico não tivesse sido visto através de uma lente feminista. A memória de Jane Addams e das mulheres que partilharam a sua visão reformista que se apresenta neste texto não é apenas uma resposta ao seu apelo, considerando que elas, como muitas outras pessoas já reconheceram, pertencem ao referido panteão do pragmatismo, mas é também uma tentativa de reforçar o conhecimento que temos da fase formativa da Universidade de Chicago, na sua contribuição para o estabelecimento da sociologia e das ligações, nomeadamente comunicativas, que se estabeleceram entre o pragmatismo clássico, o feminismo e a democracia (Elshtain, 2001; Levine, 1971).

Estas preocupações ligam, com efeito, mulheres como Jane Addams, Jessie Taft, Florence Kelley, Sophonisba Breckenridge, Edith e Julia Abbott, Alice Hamilton, Lucy Sprague Mitchell e Julia Lathrop, aos seus colegas de Chicago que o cannon imortalizou. Destes, John Dewey é certamente um dos mais imediatamente associados a essas mulheres invisíveis não só porque foi amigo próximo de algumas delas, mas especialmente porque, em muitos aspetos, ele tanto as influenciou como sofreu a sua influência.

\section{Entre o pragmatismo e o feminismo em Chicago}

Importa começar por apresentar o trabalho feminista feito em Chicago, no final do século XIX e a sua relação com o estabelecimento da sociologia nos Estados Unidos pois, embora as origens reformistas da disciplina estejam bem documentadas, o processo de transição do ativismo social para a ciência social não é tão comumente discutido.

Começamos por lembrar que na América do século XIX, para além do predomínio das ideias religiosas Calvinistas, o Capitalismo e o Liberalismo eram as duas principais ideologias dominantes, partilhando duas crenças entre si: primeiro, que o governo não deve interferir com as forças de mercado e, segundo, que a autonomia individual deveria ter como base as atitudes de responsabilidade pessoal e de autossuficiência (Franklin, 1986). Essas ideias marcaram o surgimento de uma perspectiva que dirigiu a sua atenção para os problemas de determinados indivíduos e para as suas falhas de responsabilidade pessoal. A noção liberal de democracia como um processo pelo qual os 
indivíduos procuram satisfazer as suas próprias necessidades sem ligação aos outros, de quem se espera que protejam os seus próprios interesses, encontra, no entanto, um forte oposição numa terceira perspectiva ideológica emergente: a do pragmatismo, que defendia um compromisso com a ciência e o espírito empírico (Franklin, 1986). Na verdade, o modelo pragmático de democracia é, em certos aspetos, muito diferente do modelo liberal. O pragmatismo clássico ${ }^{2}$, por detrás das formas políticas da democracia, vê outra realidade. Em vez de assumir a forma política como uma expressão de unidades isoladas de indivíduos egoístas, entende a democracia como uma forma comunicativa de associação, especialmente apropriada para pessoas constituídas pelas múltiplas relações e interações através das quais a consciência se desenvolve e os valores se desenvolvem.

John Dewey, por exemplo, reagindo aos pressupostos psicológicos do liberalismo e dos próprios economistas políticos, argumentou que não são os aspectos individuais que moldam os interesses e motivações das pessoas, mas as suas diferentes formas de associação e que, por essa razão, não se pode especular sobre a natureza humana a partir de análises dedutivas de um sistema de políticas sociais. Segundo Dewey ([1927]1991), todo o discurso intelectual está sujeito às distorções e valores dos envolvidos. O conhecimento não é a soma de algumas verdades fixas, mas o produto de investigação que, em si, é um processo contínuo. Estando todas as atividades humanas enraizadas na experiência e na interação, isto leva a um compromisso de ligar teoria e prática. Estas ideias e tônicas na ação e na experiência traduziam-se, em Dewey, na crença pragmática de que os indivíduos que viviam em situação de pobreza não eram necessariamente moralmente repreensíveis, mas influenciados por um sistema que afetava o funcionamento social e que necessitava ser analisado. Como um "método de inteligência organizada", a democracia usaria a informação espalhada disponível na sociedade, a fim de tomar decisões melhor informadas sobre assuntos de interesse público (Dewey, [1935] 1987, p. 61).

Estas ideologias intelectuais, bem como as religiosas vigentes constituíram os quadros conceituais de dois movimentos sociais emergentes que procuravam aliviar os problemas associados à pobreza:

2 Utilizamos a expressão "pragmatismo clássico" para nos referirmos ao grupo de "filosofias que foram desenvolvidas a partir do final do século XIX ao início do século XX, e foram muito influentes na Era Progressista (1890-1915) e até a Segunda Guerra Mundial. Pragmáticos, como John Dewey, William James e Jane Addams interessavam-se pela intersecção entre teoria e prática, trazendo o pensamento filosófico para a sua relação com o ambiente social e político" (Whipps, 2008). 
Os movimentos que aceitaram as ideias do liberalismo, com sua ênfase na responsabilidade e na ação individual, tenderam a dar o seu apoio à Charity Organization Society. Os que adotaram a filosofia do pragmatismo, e que se preocupavam mais com os problemas de bairros e regiões geográficas, trabalhavam no Settlement House Movement (Franklin, 1986, p. 507).

Os e as fundadoras deste último movimento, as Settlement House, viviam e trabalhavam nas vizinhanças mais pobres, procurando levar a sua educação e boa vontade para apoiar os/as mais carentes definindo os problemas ambientais da pobreza e tendo como projeto a melhoria social. Aqui se desenvolvia, de modo muito concreto, a reciprocidade entre teoria e prática, entre o conhecimento e a ação que ecoava, de modo quase perfeito, no feminismo. Essa ligação, no entanto, parece ter-se perdido, como Seigfried (1996) muito bem mostra, pelo que haverá que a retomar. A ligá-los, uma noção fundamental - a de que

feministas e pragmáticos não acham que ter valores antecedentes à teorização que os explora seja um problema para um filosofar genuíno. Lutar por um maior e mais livre crescimento das mulheres, ou lutar por florescentes comunidades humanas, não parece de todo hostil a análises cuidadosas e lógicas dos tipos de preocupações gerais e relações ligadas aos problemas que tentamos resolver. (Miller, 2013, p. 232).

\section{Jane Addams e a primeira sociologia em Chicago}

É na confluências destes movimentos que encontramos Jane Addams (1860-1935), que fez parte da primeira geração de mulheres americanas a obter um diploma universitário, no seu caso, de Rockford College, no Illinois. Depois de visitar Toynbee Hall, um social settlement universitário em Londres, Addams estabeleceu em 1889 a primeira casa semelhante, a Hull-House, em Chicago. Estes settlements eram geralmente casas de residência para licenciados que quisessem viver em áreas deprimidas e contribuir para a vida social da comunidade envolvente, através por exemplo do desenvolvimento da educação de adultos, a recolha de dados sociais e para a melhoria das condições sociais e industriais locais. Inspirada pelo exemplo britânico, Jane Addams rapidamente convenceu a amiga Ellen Starr Gates a participar na sua experiência de implementação de uma destas casas, procurando beneficiar 
muitos dos novos imigrantes e classes operárias residentes em Chicago com uma ação reformista assente na ética e, nesse sentido, distinta da vigente. Com efeito, segundo Addams, os movimentos de reforma governamentais não eram, em geral, a expressão de uma vida moral ou social:

[Os reformadores] estão quase totalmente ocupados na correção da máquina política e com uma preocupação com o melhor método de administração, em vez de terem como objetivo final a garantia do bem-estar do povo. Eles fixam a sua atenção tão exclusivamente nos métodos, que não conseguem considerar os objetivos finais do governo da cidade [...]. Tentando melhorar a situação, no entanto, eles [os reformadores] só têm em mente conquistas políticas que separam de uma forma curiosa do resto da vida, e falam e escrevem sobre a purificação da política como uma coisa distinta da vida. (Addams, 1902, p. 222-223).

Já a Hull House era

uma tentativa de aliviar, ao mesmo tempo, a sobreacumulação num extremo da sociedade e a privação no outro, mas ela [a casa] assume que esta sobreacumulação e indigência são mais fortemente sentidas nas coisas que dizem respeito aos privilégios sociais e educacionais (Addams, [1910]1990, p. 86).

Deste modo, a Casa satisfazia a "necessidade subjetiva" de ajudar as pessoas a livrarem-se do sentimento de que andavam à deriva e parecia darIhes um sentido para as suas vidas difíceis.

Não sendo uma obra de caridade, mas um local onde práxis e ação se reuniam na libertação dos mais oprimidos, a Hull House constituía-se como um lugar para desenvolver e explorar a interdependência entre as classes. Aí se desenvolveram programas educacionais e culturais, de arte, música e desporto, numa tentativa de lidar e minorar os efeitos da pobreza. Mas, na sua interação social e educativa com a vizinhança, majoritariamente constituída por imigrantes muito pobres, a Hull House viria também a constituir-se como uma instituição política, um centro de onde emanavam posições de defesa de questões como o aumento do salário mínimo, os direitos sindicais, as leis de trabalho infantil, e a prestação de melhores e não discriminatórios serviços públicos. A Casa 
foi também uma espécie de think tank do pragmatismo feminista, no qual o conhecimento individual e coletivo não era alcançado através de crenças fixas, mas nas trocas entre ideologias concorrentes e testando as teorias pela experiência mediada pela comunicação. Por todas estas razões, Addams defendeu que:

\begin{abstract}
A única coisa a recear no settlement é que ele perca a sua flexibilidade, o seu poder de adaptação rápida, a sua disponibilidade para mudar os seus métodos se o ambiente o exigir. Deve ser aberto à convicção e ter um profundo e permanente sentido de tolerância. Deve ser hospitaleiro e pronto para a experiência. Deve exigir dos seus moradores uma paciência científica na acumulação de fatos e a manutenção constante das suas empatias, como um dos melhores instrumentos para essa acumulação. Deve basear-se numa filosofia cujo fundamento está na solidariedade da raça humana, uma filosofia que não vacila quando a raça passa a ser representada por uma mulher bêbada ou por um garoto idiota. Os seus moradores têm de ser esvaziados de toda a vaidade de opinião e de toda a autoafirmação, e prontos para despertar e interpretar a opinião pública do seu bairro (Addams, [1910] 1990, p. 127).
\end{abstract}

Mas, para além do seu pioneirismo no movimento das Settlement House, Addams viria a ser uma proeminente oradora e escritora sobre um conjunto de outras causas: a profissão do trabalho social, o voto e outros direitos políticos das mulheres e o seu acesso à educação e às profissões. Além disso, grande parte da sua vida foi dedicada ao movimento de paz: ela liderou a delegação americana das primeiras mulheres ao Congresso sobre a paz em Haia, e foi a presidente fundadora da Liga Internacional das Mulheres para a Paz e Liberdade, formada nesse congresso, tendo recebido o Prémio Nobel da Paz, em 1931, por este trabalho.

Mas o que nos ocupa neste texto é sobretudo a sua associação com John Dewey. Addams conheceu-o mesmo antes de ele ter ido para Chicago e juntamente com George Herbert Mead, estiveram envolvidos no movimento das Settlement House (Simonson, 2001). Ambos partilharam uma série de crenças, nomeadamente a valorização de uma democracia robusta e a importância da educação que envolvia a experiência dos alunos. Dewey era um visitante frequente da Hull House e Addams muitas vezes dava palestras na Universidade de Chicago, onde ele era professor. Dewey também frequentemente usava os 
livros de Addams nas suas aulas e dedicou-lhe o seu texto de 1935, Liberalism and social action.

O Departamento de Sociologia da Universidade de Chicago - o primeiro no país - foi também criado em 1892. Mary Jo Deegan (1988), no livro Jane Addams e os homens da Escola de Chicago, argumenta que a tradição dos estudos urbanos remonta a uma sociologia iniciada em Chicago comprometida com as reformas progressistas e cujo principal crédito vai para a rede de mulheres sociólogas reunidas em torno de Jane Addams. A principal razão para o posterior abandono desta contribuição precoce viria a ser, segundo Deegan, a postura machista e cada vez mais apolítica e antirreformista desenvolvida pelos sociólogos de Chicago, em 1920. Por isso, a autora argumenta que Jane Addams deve ser reintegrada na sua devida posição como uma importante contribuinte para a sociologia da Escola de Chicago e do tempo que se Ihe seguiu, o mesmo acontecendo com as muitas outras mulheres da época, particularmente as que estavam associadas à Hull-House, cujas contribuições foram esquecidas ou redefinidas como (simplesmente) trabalho social.

Deegan (1988) argumenta ainda que havia uma tradição sociológica feminina diferenciada, baseada nas Settlement Houses e fortemente preocupada com a reforma social; essas mulheres muitas vezes não estavam preparadas para aceitar as restrições políticas dos empregos na universidade, e quando os tinham, eram discriminadas e rotuladas na área estereotipada como feminina, a do "trabalho social". No entanto, realizaram um forte corpo de pesquisa empírica sistemática, muita dela quantitativa, numa época em que isso era raro na academia masculina.

Os Mapas e Textos das Hull-House - um volume de investigações e reflexões sociológicas originais publicadas em 1895 - foram um trabalho pioneiro que teve um papel-chave - embora mais tarde não reconhecido na tradição de Chicago do mapeamento social. Na verdade, muito antes de Park e Burgess articularem o seu programa de pesquisa, as sociólogas do sexo feminino estiveram envolvidas em pesquisa de campo, preparando o terreno para o que mais tarde se seguiria. Particularmente impressionante eram, como já referimos, os mapas multicoloridos que retratavam a distribuição demográfica dos residentes na região vizinha - a técnica que mais tarde se tornaria uma marca da sociologia de Chicago.

As mulheres da Hull House criaram uma sociologia distintiva fortemente infundida por um conjunto de teorias críticas, incluind o o marxismo, o feminismo e o "pragmatismo crítico", como Ihe chama Deegan. Metodologicamente, rejeitaram o modelo de investigação/observação distanciada, defendendo um 
discurso contínuo entre todos os membros da comunidade, independentemente da sua classe, sexo, raça ou etnia, como um meio para a identificação de problemas, investigação, educação e ação benéfica. Além disso, trabalharam como um coletivo sociológico na comunidade, rejeitando "distinções entre teoria e prática, pública e privada, profissional e quotidiana, no trabalho e em casa" (Deegan, 1988, p. 49).

Recordemos ainda que Addams, se não tem um contributo direto para o desenvolvimento da comunicação, foi uma das primeiras a comentar a influência do cinema nas crianças e no seu desenvolvimento. Nesse sentido, devotou a esse tema todo um capítulo do seu livro The spirit of youth and the City Streer - um excerto do qual John Durham Peters e Peter Simonson incluem na sua antologia sobre comunicação e pensamento social americano - numa análise a que ela chamou a "Casa dos Sonhos" ([1901] 2004). Aí, a autora mostrase bastante ambivalente sobre o assunto. Com efeito, reconhecendo o papel recreativo do cinema para a criança da cidade, também se mostra receosa sobre os seus possíveis efeitos nefastos dizendo:

Deixar de fornecer recreação à juventude não é apenas privá-la da sua forma natural de expressão, mas é certo que alguns [jovens] se sujeitam à tentação irresistível do ilícito e dos prazeres destruidores da alma. Insistir que os jovens só devem ver o seu futuro cor de rosa numa casa dos sonhos, é privá-los do mundo real desse calor e tranquilidade de que eles tanto certamente necessitam e a que têm justamente direito (Addams, [1901] 2004, p. 29).

Mas, para além destas referências mais explícitas às formas mediáticas, encontramos em Addams, como no pragmatismo da Escola de Chicago, um entendimento da comunidade como forma de comunicação, em que esta tem o seu valor epistemológico de "pôr em comum", dando à comunicação um papel central na definição das nossas vidas individuais e coletivas e na consolidação das nossas identidades e comunidades (Silveirinha, 2004).

Num controverso argumento, Mary Jo Deegan (1988) acusa a "ideologia patriarcal", o conservadorismo político e o profissionalismo estúpido de homens como Robert E. Park, de ter esmagado a tradição "feminista cultural". É difícil, no entanto, dizer o que poderia ter acontecido se as mulheres pioneiras da ciência social não tivessem sido votadas à invisibilidade.

Em todo o caso, graças a uma série de sociólogas e filósofas feministas, bem como a alguns sociólogos comunicação, não apenas Jane Addams, mas 
muitas outras mulheres têm sido reintegradas na sua devida posição como importantes contributos para a sociologia da Escola de Chicago, do seu tempo e do que se seguiu e, em especial, para o estabelecimento do pragmatismo comunicacional. Peter Simonson, por exemplo, inclui Jane Addams numa categoria de pragmatismo que, juntamente com George Santayana, W. E. B. Du Bois, Alain Locke, Walter Lippmann, and C. Wright Mills "levaram a tradição para além do establishment Yankee Protestante Branco e masculino e desenvolveram a estética do pragmatismo, a crítica, a sociologia, a política e teoria racial" (Simonson, 2001, p. 2). A este grupo pertence certamente também Charlotte Perkins Gilman (Upin, 1993).

O trabalho de Addams deve, por fim, ser reconhecido por uma série de razões: ensinou cursos universitários, era um membro ativo da Sociedade Americana de Sociologia, escreveu uma dezena de livros e inúmeros artigos de filosofia social original, reconhecidos por seus contemporâneos como John Dewey, William James e George Herbert Mead. Na verdade, como já referimos, Jane Addams mantinha estreitas relações intelectuais com estes primeiros sociólogos em Chicago e a Hull-House era importante para eles. No entanto, de todas estas relações, as amizades com G. H. Mead, W. I. Thomas e John Dewey são intelectualmente as mais importantes.

Por outro lado, a estreita associação de Dewey com a Hull-House durante o seu tempo na Universidade de Chicago, bem como a sua amizade com Jane Addams, têm sido bem documentadas. De acordo com Christopher Lasch, é "difícil dizer se Dewey influenciou Jane Addams ou se Jane Addams influenciou Dewey. Eles influenciaram-se mutuamente e generosamente reconheceram as suas influências mútuas" (Lasch, 1965, p. 176). Ou, como eloquentemente diz Knight (2005, p. 240), "à medida que os anos passaram, não foi Dewey que influenciou Addams ou Addams que influenciou Dewey, mas a amizade que influenciou ambos" - e essa influência é importante para o feminismo.

\section{O contributo de John Dewey para uma ética feminista da comunicação}

É certo que quase nada se disse sobre os escritos de John Dewey sobre as mulheres porque, na verdade, ele escreveu muito pouco sobre o assunto e, mesmo tendo frequentemente reconhecido, em termos privados, a influência das feministas, ele "não as reconheceu na sua escrita acadêmica", num silêncio que seria perpetuado pelos pragmáticos que se Ihe seguiram (Shuler; Tate, 2001, p. 213) . A ausência do reconhecimento da influência de autoras como Jane Addams da Hull House e de Lucy Sprague Mitchell na Bank Street é, como 
também refere Marjorie Miller (2013), um dos sinais do lado patriarcal de um John Dewey mais ostensivamente feminista, já que os benefícios da associação comum entre ele e essas mulheres não resultaram em formas explícitas que permitam o reconhecimento pleno e público da sua influência sobre suas ideias.

Apesar disso, há evidências nos seus escritos - bem como na sua vida - de que ele acreditava que o lugar das mulheres na sociedade era determinado pelo seu ambiente e não apenas pela sua biologia. Portanto, como recorda Jane Upin (1993), ao contrário de muitos dos seus contemporâneos do sexo masculino, ele foi capaz de ver além de alguns dos estereótipos sobre as mulheres vitorianas e começar a fazer um "diagnóstico" das dificuldades que as mulheres enfrentam. No início de sua carreira, fez notar que "a teoria predominante da natureza essencialmente conservadora de inteligência da mulher [é apenas] uma ficção da inteligência masculina, mantida a fim de manter sob controle o [seu] radicalismo inconveniente" (Dewey, 1894, citado por Upin, 1993, p. 51).

Comentando sobre costumes primitivos, destacou a forma como os homens mantiveram "a ocupação da caça para si mesmos" e atribuíram às mulheres "todo o tipo de trabalho penoso", e especificamente chamou a atenção para as consequências contínuas dessa divisão sexual precoce do trabalho (Dewey, 1902, citado por Upin, 1993, p. 51). Além disso, apoiou a batalha pela coeducação, em 1902, na Universidade de Chicago e reconheceu o seu "endividamento fundamental" para com as mulheres que haviam trabalhado na escola-laboratório (Dewey, [1910] 1978, p. 179). Em 1930, fez notar que

as atuais ideias sobre o amor, o casamento e a família são construções quase exclusivamente masculinas. Como todas as idealizações dos interesses humanos que expressam uma experiência unilateral, são românticas em teoria e prosaicas no seu funcionamento (Dewey, [1930] 1984, p. 276).

Prevê ainda que "a crescente liberdade das mulheres não pode ter outro resultado que não a produção de uma moral mais humana e mais realista"(Dewey, [1930] 1984, p. 276). Esta previsão de Dewey sobre a influência das mulheres nos futuros destinos da ética, no entanto, não seria tão facilmente traduzida quanto ele previa. Com efeito, muitas feministas - em especial as influenciadas por Carol Gilligan (1982) - continuam a acusar as abordagens éticas tradicionais de conterem uma distorção masculina, contrapondo-lhe frequentemente a "voz do cuidado", como uma alternativa legítima à "perspetiva de justiça" da teoria 
liberal dos direitos humanos, que pode ser igualmente equacionada para o campo da comunicação e dos media (Camponez, 2014). Por outro lado, mesmo que haja diferenças significativas entre as eticistas feministas de hoje, todas elas concordam que há algumas noções morais, esferas e problemas que têm sido desvalorizados, negligenciados ou ignorados na ética ocidental tradicional. Entre essas questões estão o afetivo (emoções), a estética, e a primazia das relações pessoais (por exemplo, relações maternais, família, amizade).

Apesar das diferentes direções que a ética viria a tomar, importa registrar que John Dewey fornece bases que são aceitáveis do ponto de vista feminista e que podem ser importantes para a transformação feminista da ética. Para além de argumentar contra a desvalorização do afetivo, a estética e as relações concretas, a sua ética contém uma apreciação cuidadosa de como e porquê essas coisas são essenciais para a nossa vida moral, numa perspetiva que nunca perde o pragmatismo de vista. Por isso, Charlene Haddock Seigfried sugeriu que nós só recentemente começamos a explorar "os benefícios mútuos de um pragmatismo feminista e de um feminismo pragmático" (Seigfried, 1991, p. 2). Por outro lado, como Gregory Fernando Pappas (1993, p. 79) argumenta, o pragmatismo contemporâneo deve ter presente "de quão sério é o compromisso de Dewey com os aspetos da experiência que têm sido associados com as mulheres (ou o 'feminino')".

Para Dewey o afetivo não é periférico ou um subproduto da vida ética. Nos seus escritos, encontramos uma rica noção de inteligência em que o afetivo é fundamental para uma explicação adequada de investigação moral e de um bom caráter moral, sendo geradora das qualidades estéticas da experiência. Isto contraria a noção tradicional de como o afetivo foi concebido: como um obstáculo ou como apresentando perigos para a objetividade necessária e universalidade do conhecimento moral. A perspetiva pragmática, tal como a de algumas feministas, não pode fazer sentido de um ponto de vista imparcial e universal que nada é em particular. Dewey, como recorda Gregory Pappas (1993, p. 83) de novo, "não descarta qualquer emoção como moralmente irrelevante, mas dá razões pelas quais a empatia é o afeto mais importante para a investigação moral e para um bom caráter". Com a ajuda da empatia podemos chegar mais perto de um ponto de vista intelectual, que pode ser útil para a deliberação moral. Colocar-nos emocionalmente no lugar do outro é a única forma de ampliar o nosso horizonte intelectual e determinar de forma eficaz o que os outros precisam e valorizam. Mas Dewey também compreende os perigos de isolar e enfatizar excessivamente a empatia, o cuidado ou qualquer outra emoção altruísta na moral. Essas emoções precisam ser balizadas por outras 
dimensões da nossa personalidade (Pappas, 1993). Por isso, apenas o cuidado inteligente é fundido com outros traços de personalidade não caindo no tipo de cuidado prejudicial que embrutece o crescimento das pessoas cuidadas. Temos que abrir espaço na ética não apenas para a emoções altruístas, mas para a interação orgânica entre elas e as outras virtudes de caráter.

O que torna Dewey tão radical e ao mesmo tempo tão importante para o pensamento feminista é que, para ele, as reformas necessárias à democracia não se devem limitar ao social, ao político e ao econômico, mas devem tocar também as próprias relações humanas. Diz Pappas:

\begin{abstract}
O questionamento ético precisa começar com a experiência como a encontramos. O que se encontra na experiência moral é a interação e não a imagem tradicional de uma consciência moral isolada com deveres e desejos como suas posses. Para Dewey a moral é 'social' na medida em que a interação é um fato primordial da experiência moral quotidiana (Pappas, 1993, p. 88).
\end{abstract}

É portanto necessária uma democratização do quotidiano e das relações humanas que o preenchem, incluindo a família, mas também outras instituições do "cuidado". E é também isto que constitui a chave da Grande Comunidade: "Inclino-me a acreditar que o coração e a garantia final da democracia está nos encontros livres de vizinhos na esquina da rua [...] e nas reuniões de amigos nas salas das casas e apartamentos" (Dewey, [1939] 1988, p. 227).

\title{
Notas conclusivas
}

Concluímos voltando à Hull House e às suas mulheres residentes. Aí, podemos compreender o sentido de ética, mas também o de comunidade como Dewey o defendeu, na sua ideia cultivada de grupos e indivíduos que têm uma dependência mútua, entendendo-se como elementos de um organismo social maior.

Judy D. Whipps (2004) recorda-nos que no seu primeiro ensaio publicado em 1892, Addams refere-se ao mundo social que partilhamos juntos como um "organismo social", uma entidade viva composta por indivíduos como elementos orgânicos de um todo. Este termo refere-se a uma compreensão da inter-relação viva: nós, como seres humanos estamos unidos de uma forma em que uma parte afeta o todo. Tais metáforas orgânicas para a sociedade eram 
comuns nas discussões políticas e filosóficas final do século XIX e encontramolas na filosofia inicial de Dewey, bem como no trabalho de outros escritores neo-hegelianos da época. Mas nos primeiros anos da Hull House, o foco era na interdependência: nomeadamente, a que unia as classes sociais e econômicas, fazendo sentir que os homens e mulheres das classes mais elevadas precisavam do settlement tanto ou mais do que as subclasses pobres no gueto.

Addams alegou que as condições de interdependência realizavam a promessa de civilização, cooperação e convivência e trabalhou para construir comunidades que promoveram essas associações. As suas comunidades eram ricas, plurais, orgânicas. Como refere Marjorie Miller:

\begin{abstract}
As comunidades que Addams construiu ou em que estava envolvida foram sempre diversas, e sempre críticas e criativas. Elas não eram ninhos de tradição quentes, distorcidos. Eram ousadase experimentais e visavam melhorar problemas mutuamente reconhecidos e a criação de possibilidades partilhadas. Nem todas eram locais ou face a face. Mas foi o seu engajamento na comunidade de Hull House que deu a Addams a base para desenvolver a inteligência social que lhe permitiu reconhecer continuamente novos problemas - não apenas para gerar novas soluções. (Miller, 2013, p. 243).
\end{abstract}

A interdependência, como condição de comunidade, fez as mulheres da Hull House reconhecerem as obrigações comunitárias e agirem em função destas obrigações por meio de ações tão variadas como serem inspetoras de lixo, produzirem investigações sobre saneamento, evasão escolar, tuberculose, mortalidade infantil e uso de cocaína em Chicago, provocar mudanças nas leis e programas públicos, apostar na investigação sobre segurança industrial, ou pessoalmente, ajudando nos partos. $E$ foi este sentido de interdependência com os outros que as levaria a participar na defesa internacional do sufrágio e, mais tarde, nas organizações pacifistas.

Hoje, o contributo das mulheres para a ciência social e para a comunicação em particular vai sendo crescentemente conhecido (ver, por exemplo, a recente contribuição de Rowland e Simonson, 2014)3. As pioneiras da ciência prática da comunidade orgânica parecem hoje esquecidas, nos tempos individualistas e neoliberais que levaram, por exemplo, em 2012, ao fecho da Hull House Association, tempos em que o político parece ter se esvaziado e a comunicação

3 Ver também o site: <http://www.outofthequestion.org $>$. 
parece equivaler a pouco mais do que ruído no imperativo econômico. Vivemos num mundo orientado por valores corporativos e mediáticos materiais, atravessado de tentativas concorrenciais para alcançar a vida individual quantificada que nos é apresentada como ideal, necessária, lógica e imperativa. Mas talvez por isso mesmo, hoje, mais do que nunca, devamos fazer eco das palavras de Addams:

Estamos todos envolvidos nesta corrupção política, e como membros da comunidade, indiciados. Esta é a pena de democracia - que somos obrigados a seguir em frente ou para trás, juntos. Nenhum de nós pode ficar de lado, os nossos pés estão atolados no mesmo solo, e nossos pulmões respiram o mesmo ar (Addams citado por Seigfried, 1999, p. 226).

Quando começamos a ligar os pontos deste tipo de envolvimento e ação permitimo-nos viver como seres que se sentem e percebem como conectadosem-geral. Mas aqui, a conexão que tendencialmente percebemos hoje apenas como mediaticamente global ganha contornos ético-políticos: seja através da conexão radical de Dewey ou dos todos orgânicos de Addams e dos feminismos que se lhe seguiram, trata-se de colocar a comunicação e a comunidade no cerne de todos os envolvimentos pragmáticos das nossas vidas individuais e coletivas.

\section{Referências}

ADDAMS, Jane. Democracy and social ethics. New York: Macmillan Co, 1902.

The house of dreams. In: Peters, John Durham; Simonson, Peter. Mass communication and american social thought: key texts, 1919-1968. Lanham: Rowman \& Littlefield, [1901] 2004, p. 25-30.

ADDAMS, Jane. Twenty years at Hull-house; with autobiographical notes. Urbana: University of Illinois press, [1910]1990.

CAMPONEZ, José Carlos. Entre verdade e respeito - por uma ética do cuidado no jornalismo. Comunicação e Sociedade, v. 25, p. 110-123, 2014. Disponível em: $<$ http://revistacomsoc.pt/index.php/comsoc/article/view/1863/1790>. Acesso em: 19 maio. 2015. 
DEEGAN, Mary Jo. Jane Addams and the men of the Chicago School, 1892-1918. New Brunswick:Transaction, 1988.

DEWEY, John. How we think. In: Boydston, Jo Ann (Ed.). The middle works of John Dewey, 1899-1924, v. 6. Carbondale and Edwardsville: Southern Illinois University Press, [1910] 1978, p. 177-356.

. The public and its problems. Athens: Swallow Press, [1927] 1991.

.What I believe. In: Boydston, Jo Ann (Ed.). John Dewey: the later works, 1925-

1953, v. 5. Carbondale and Edwardsville: Southern Illinois University Press, [1930] 1984, p. 267-278.

. Liberalism and social action. In: Boydston, Jo Ann (Ed.). John Dewey: the later works, 1925-1953, v. 11. Carbondale and Edwardsville: Southern Illinois University Press, [1935] 1987, p. 1-65.

. Creative democracy - the task before us. In: Boydston, Jo Ann (Ed.). John Dewey: the later works, 1925-1953, v. 14. Carbondale and Edwardsville: Southern Illinois University Press, [1939] 1988, p. 224-230.

ELSHTAIN, Jean Bethke. Jane Addams and the dream of american democracy. New York: Basic Books, 2001.

FRANKLIN, Donna L. Mary Richmond and Jane Addams: from moral certainty to rational inquiry in social work practice. Social Service Review, v. 60, n. 4, p. 504525, 1986. Disponível em: <http://dx.doi.org/10.1086/644396 >. Acesso em: 19 maio. 2015.

GILLIGAN, Carol. In a different voice: psychological theory and women's development. Cambridge: Harvard University Press, 1982.

KNIGHT, Louise. Citizen: Jane Addams and the struggle for democracy. Chicago: University of Chicago Press, 2005.

$\mathrm{LASCH}, \mathrm{Christopher.} \mathrm{Introduction} \mathrm{to} \mathrm{the} \mathrm{social} \mathrm{thought} \mathrm{of} \mathrm{Jane} \mathrm{Addams.} \mathrm{Indianapolis:}$ Bohhs-Merrill, 1965.

LEVINE, Daniel. Jane Addams and the liberal tradition. Madison: State Historical Society of Wisconsin, 1971.

MILLER, Marjorie C. Pragmatism and feminism. In: Malachowski, Alan. (Ed.). The Cambridge companion to pragmatism. Cambridge: Cambridge University Press, 2013, p. 231-248.

OUT OF THE QUESTION. Disponível em: < http://www.outofthequestion.org >. Acesso em: 19 maio . 2015. 
PAPPAS, Gregory Fernando. Dewey and Feminism: The affective and relationships in Dewey's ethics. Hypatia, v. 8, n. 2, p. 78-95, spring, 1993. Disponível em: $<\underline{\text { http:// }}$ www.jstor.org/stable/3810338? seq=1\#page scan tab contents $>$. Acesso em: 19 maio. 2015.

ROWLAND, Allison L.; SIMONSON, Peter. The founding mothers of communication research: toward a history of a gendered assemblage. Critical Studies in Media Communication, v. 31, n. 1, p. 3-26, 2014. Disponível em: <http://www. tandfonline.com/doi/abs/10.1080/15295036.2013.849355>. Acesso em: 19 maio de 2015.

http://dx.doi.org/10.1080/15295036.2013.849355

SEIGFRIED, Charlene Haddock. Where are all the pragmatist feminists? Hypatia, v. 6, n. 2, p. 1-19, 1991.

http://dx.doi.org/10.1111/j.1527-2001.1991.tb01390.x

SEIGFRIED, Charlene Haddock. Pragmatism and feminism: reweaving the social fabric. Chicago: University of Chicago Press, 1996.

Socializing democracy: Jane Addams and John Dewey. Philosophy of the Social Sciences, v. 29, n. 2, p. 207-230, jun. 1999. Disponível em: <http://pos. sagepub.com/content/29/2/207.abstract>. Acesso em: 19 maio. 2015.

http://dx.doi.org/10.1177/004839319902900203

SILVEIRINHA, Maria João. Identidades, media e política. Lisboa: Livros Horizonte, 2004.

SIMONSON, Peter. Varieties of pragmatism and communication: visions and revisions from Peirce to Peters. In: Perry, David K. (Ed.). American pragmatism and communication research. Mahwah: Lawrence Erlbaum Associates, 2001, p. $1-27$.

SHULER, Sherianne; TATE, Melissa. Intersections of feminism and pragmatism: possibilities for communication theory and research. In: Perry, David K. (Ed.). American pragmatism and communication research. Mahwah: Lawrence Erlbaum Associates, 2001, p. 209-223.

UPIN, Jane. Charlotte Perkins Gilman: instrumentalism beyond Dewey. Hypatia, v. 8, n. 2, spring, p. 38-63, 1993. Disponível em: <http://www.jstor.org/ stable/3810336? seq=1\#page scan tab contents $>$. Acesso em: 19 maio. 2015.

WHIPPS, Judy D. Jane Addams's social thought as a model for a pragmatist-feminist communitarianism. Hypatia, v. 19, n. 2, p. 118-133, spring, 2004. Disponível em: $<$ https://muse.jhu.edu/article/170260>. Acesso em: 19 maio .2015. ] 
Pragmatist feminism. In: Zalta, Edward N. (Ed.). The Stanford encyclopedia of philosophy. Disponível em: <http://plato.stanford.edu/archives/fall2008/ entries/femapproach-pragmatism/>. Acesso em: 19 maio. 2015.

Recebido em: 27/12/2015

Aceito em: 2/3/2016

Endereço do autor:

Maria João Silveirinha <mjsilveirinha@sapo.pt>

Faculdade de Letras da Universidade de Coimbra, FLUC.

Largo da Porta Férrea.

3004-530 - Coimbra - Portugal. 